\title{
Phylogenetics of wigeons and allies (Anatidae: Anas): the importance of sampling multiple loci and multiple individuals
}

\author{
Jeffrey L. Peters ${ }^{\mathrm{a}, *}$, Kevin G. McCracken ${ }^{\mathrm{b}}$, Yuri N. Zhuravlev' ${ }^{\mathrm{c}}$, Yi Lu ${ }^{\mathrm{a}}$, Robert E. Wilson ${ }^{\mathrm{b}}$, \\ Kevin P. Johnson ${ }^{\mathrm{d}}$, Kevin E. Omland ${ }^{\mathrm{a}}$ \\ ${ }^{a}$ Department of Biological Sciences, University of Maryland Baltimore County, Baltimore, MD 21250, USA \\ ${ }^{\mathrm{b}}$ Department of Biology and Wildlife \& Institute of Arctic Biology, University of Alaska Museum, University of Alaska Fairbanks, \\ Fairbanks, AK 99775, USA \\ ${ }^{\mathrm{c}}$ Institute of Biology and Soil Science, Far East Branch, Russian Academy of Sciences, Vladivostok 690022, Russia \\ ${ }^{\mathrm{d}}$ Illinois Natural History Survey, 607 East Peabody Drive, Champaign, IL 61820, USA
}

Received 7 May 2004; revised 20 December 2004

Available online 29 January 2005

\begin{abstract}
Species-level DNA phylogenies frequently suffer from two shortcomings — gene trees usually are constructed from a single locus, and often species are represented by only one individual. To evaluate the effect of these two shortcomings, we tested phylogenetic hypotheses within the wigeons and allies, a clade of Anas ducks (Anatidae) composed of five species. We sequenced two nuclear introns from the Z-chromosome-linked chromo-helicase binding protein gene (CHD1Zb and CHD1Za) and the mitochondrial DNA (mtDNA) control region for multiple individuals sampled from widespread geographic locations. We compared these phylogenies to previously published phylogenies constructed from morphology and protein coding regions of mtDNA. Relative to other nuclear introns, CHD showed remarkable phylogenetic utility. Of the $26 \mathrm{CHD} 1 \mathrm{Zb}$ alleles identified, only one was shared between two species, and the combined CHD datasets revealed that four of the five species were consistent with monophyly. Several species shared mtDNA haplotypes, which probably was a result of interspecific hybridization. Overall, the nuclear CHD tree and the mtDNA tree were more congruent with coding regions of mtDNA than they were with morphology.
\end{abstract}

(C) 2005 Elsevier Inc. All rights reserved.

Keywords: Phylogenetics; Nuclear intron; CHD; mtDNA; Anas; Wigeon; Gadwall; Falcated duck

\section{Introduction}

Constructing phylogenetic trees from DNA sequences has become standard practice, but many molecular phylogenetic analyses suffer from two shortcomings. First, the vast majority of animal species-level studies have relied solely on mitochondrial DNA (mtDNA). Although high mutation rates, low effective population size, and lack of recombination make

\footnotetext{
* Corresponding author. Fax: +1 4104553875 .

E-mail address: jpeters1@umbc.edu (J.L. Peters).
}

mtDNA an excellent marker (Avise et al., 1987; Moore, 1995; Moritz et al., 1987), mtDNA is a single linkage group that can be susceptible to stochastic lineage sorting and hybridization, either of which can mislead phylogenetic inferences (Avise, 2000; Ballard and Whitlock, 2004; Funk and Omland, 2003; Palumbi et al., 2001). A second shortcoming of many species-level phylogenies is that only one or a few representatives of each taxon are sampled (Funk and Omland, 2003; Omland, 1997). In a review of mtDNA phylogenetic and phylogeographic studies, Funk and Omland (2003) found that $17 \%$ of 331 bird species had species-level paraphyly or polyphyly; some individuals of a species had mtDNA that was more 
similar to other species than to conspecifics. Hence, phylogenetic relationships among closely related species are often more complex than can be suggested by the inclusion of a single representative (also see Omland et al., 1999). To obtain a better understanding of species-level phylogenetics, studies should evaluate multiple genetic loci (Hare, 2001; Prychitko and Moore, 1997) and attempt to include multiple individuals of each species from widespread geographical locations (Funk and Omland, 2003).

Nuclear introns provide independent characters for phylogenetic analyses, and several studies have found these markers to be useful at resolving deep phylogenetic relationships, such as at the genus and familial levels (e.g., Armstrong et al., 2001; Barker, 2004; Johnson and Clayton, 2000b; Shapiro and Dumbacher, 2001). However, the ability of introns to resolve relationships among closely related taxa has shown less promise (e.g., Allen and Omland, 2003; DeBry and Seshadri, 2001; Johnson and Clayton, 2000a). Nuclear introns accumulate substitutions at slower rates than mtDNA (Brown et al., 1979) and often do not offer sufficient resolving power to determine the relationships among closely related species. Even if nuclear introns contain enough substitutions to give phylogenetic signal, their slower lineage sorting rate, relative to mtDNA (Moore, 1995; Palumbi et al., 2001), increases the likelihood that species will not have sorted to monophyly (all intraspecific alleles sharing a more recent common ancestor with each other than with heterospecific alleles). However, Z-chromosomelinked loci may have higher phylogenetic utility than autosomal loci. First, Z-linked loci have three-quarters the effective population size of autosomal loci (males carry two Z-chromosomes, whereas females carry one), and therefore, they are expected to sort slightly more rapidly. In addition, Z-linked loci should undergo recombination only two-thirds as often as autosomal loci, because one-third of gametes for Z-linked loci segregate in the heterogametic sex where recombination presumably does not occur. Furthermore, mutation rates tend to be higher within the male genome than the female genome (e.g., Ellegren and Fridolfsson, 1997; Fridolfsson and Ellegren, 2000; Kahn and Quinn, 1999; Montell et al., 2001). Hence, Z-linked loci should accumulate mutations slightly more rapidly than autosomal loci. Finally, by sequencing females, one can avoid scoring alleles occurring in heterozygotes. CHD is a sexlinked gene, present on both the W- and Z-chromosomes, that codes for a chromo-helicase DNA binding protein (Ellegren and Fridolfsson, 1997; Fridolfsson and Ellegren, 1999). W- and Z-copies are highly divergent and chromosome-specific primers can be used to preferentially amplify the Z-copy. Pitra et al. (2002) sequenced CHD introns for phylogenetic analyses, but they did not provide a CHD tree. In this study, we further investigate the utility of CHD for phylogenetic studies.
Ducks of the genus Anas provide an excellent model system for evaluating multiple loci and the importance of sampling multiple individuals for testing phylogenetic hypotheses. Phylogenetic analyses have been conducted for the majority of Anas species, as well as several closely related genera, using morphology (Livezey, 1991) and mtDNA ND2 and cytochrome $b$ sequences (Johnson and Sorenson, 1998, 1999). Analyses also have been conducted using a variety of additional character sets, although taxon sampling was less intensive in these studies (Donne-Gousse et al., 2002; Kessler and Avise, 1984; Patton and Avise, 1986; Tuohy et al., 1992). In many aspects, trees constructed from different sets of characters are similar (see Omland, 1994), but Johnson and Sorenson (1999) found significant incongruence between the phylogenies of Livezey (1991) and Johnson and Sorenson (1998). Hence, analyses of additional independent characters are needed to test these phylogenetic hypotheses.

Within Anas ducks, sampling mtDNA from one individual may not be representative of the species. This genus underwent a rapid radiation in the past few million years (Johnson and Sorenson, 1999), and there may have been an insufficient amount of time for mtDNA to have sorted to reciprocal monophyly for several closely related species (Avise et al., 1990; Johnson and Sorenson, 1999; McCracken et al., 2001; Omland, 1997). In addition, several species of Anas ducks have widespread geographical distributions that extend across multiple continents. Such widely distributed species may harbor cryptic lineages that are not revealed by sampling a single individual (e.g., Avise et al., 1992; Omland et al., 2000; Talbot and Shields, 1996; Zink et al., 1995). Finally, dabbling ducks are well known for their capacity to hybridize, and such hybridization often produces fertile offspring (Johnsgard, 1960; Tubaro and Lijtmaer, 2002; see also Rhymer and Simberloff, 1996). Interspecific hybridization may explain the polyphyletic relationships observed in some groups of ducks (e.g., mallards; Kulikova et al., 2004; McCracken et al., 2001; Rhymer et al., 1994), and hence can lead to incorrect inferences if a single individual is sampled. Overall, these characteristics of Anas ducks increase the likelihood of species-level paraphyly and polyphyly and the probability that a single individual will not be representative of the species.

In this study, we focus on the wigeons and their allies, a monophyletic clade of Anas ducks that consists of five species that are approximately $0.5-4.7 \%$ divergent based on mtDNA cytochrome $b$ and ND2 sequences (see Johnson and Sorenson, 1998). The wigeons and allies [Livezey's (1991) genus Mareca, Johnson and Sorenson's (1999) "wigeon clade"] include the three wigeon species Anas penelope (Eurasian wigeon), A. americana (American wigeon), and $A$. sibilatrix (Chilóe wigeon), as well as $A$. strepera (gadwall) and $A$. falcata (falcated duck). Morphology and mtDNA agree in grouping these five 
A mtDNA

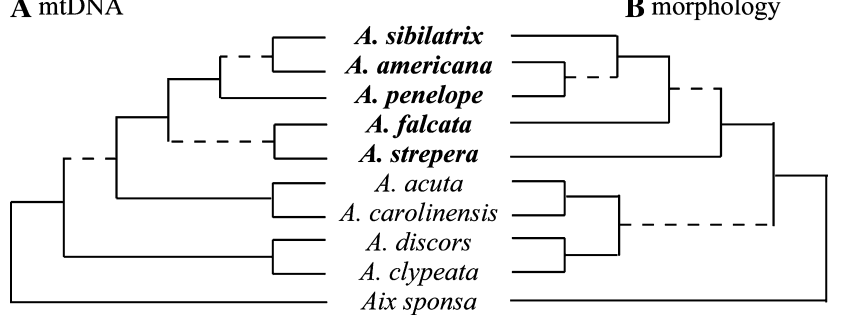

Fig. 1. Phylogenetic relationships among a subset of Anas ducks based on: (A) mtDNA ND2 and cytochrome $b$ sequences (Johnson and Sorenson, 1998, 1999) and (B) morphology (Livezey, 1991). The wigeons and allies are shown in bold type; dashed lines connect the three nodes that disagree between mtDNA and morphology.

species as each other's closest relatives, but the relationships inferred by mtDNA and morphology differ within the clade (Fig. 1; Johnson and Sorenson, 1998, 1999; Livezey, 1991). Morphology supports a sister relationship between $A$. penelope and $A$. americana, placing $A$. sibilatrix in a basal position. However, mtDNA suggests that the divergence of $A$. penelope predated the divergence of $A$. americana and A. sibilatrix. Furthermore, morphology supports a sister relationship between $A$. falcata and the three wigeon species, with $A$. strepera basal to these four species, but mtDNA supports a sister relationship between $A$. strepera and $A$. falcata to the exclusion of the wigeons.

In addition to the within-clade incongruence between morphology and mtDNA, there also is disagreement in the placement of the wigeons and allies within the Anas phylogeny. Morphology suggests a sister relationship between this group and all other Anas ducks, which led Livezey (1991) to suggest elevating the wigeons and allies to genus Mareca. However, mtDNA suggests a sister relationship between the wigeons and allies and most other Anas ducks (Fig. 1B), including pintails, mallards, green-winged ducks, and Australasian teals, but to the exclusion of the blue-winged ducks (Johnson and Sorenson, 1998, 1999). Hence, Johnson and Sorenson's (1998, 1999) data clearly place the wigeons and allies as nested within Anas (Fig. 1A). In this study, we further evaluate the phylogenetic relationships within the wigeons and allies by sequencing sex-linked CHD nuclear introns and the mtDNA control region, and by sampling multiple individuals from widespread geographic locations. We also evaluate the placement of this group within Anas ducks using CHD.

\section{Materials and methods}

\subsection{Sample collection}

Each of the five wigeons and allies was densely sampled ( $n=10-22$ individuals for each species), and sam- pling was geographically widespread for all species, except $A$. falcata (Fig. 2). Muscle tissue was provided by museums or collected at the United States and the Canadian hunter wing surveys, feathers were salvaged from dead birds, and foot-webbing and blood were collected from captured birds (Appendix). There was no indication that nuclear pseudogenes of mitochondrial DNA origin (numts, Sorenson and Fleischer, 1996) were amplified from the blood. All ducks sampled were from the wild, except one $A$. falcata and one $A$. sibilatrix from captivity. We also sampled one individual each of $A$. acuta (Northern pintail), A. crecca carolinensis (North American green-winged teal), A. clypeata (Northern shoveler), A. discors (blue-winged teal), and Aix sponsa (North American wood duck). We retrieved homologous ingroup and outgroup mtDNA control region sequences from GenBank, including $A$. strepera (AY112944), A. sibilatrix (AY112944), A. sibilatrix (AY112943), A. platyrhyncos (mallard; AY112938), A. acuta (Northern pintail; AY112939), and A. crecca cre$c c a$ (Eurasian common teal; AY112942) (Donne-Gousse et al., 2002).

\subsection{Laboratory methods}

DNA was extracted from samples using the DNeasy Tissue Kit (Qiagen, Valencia, CA, USA). We amplified $270-271 \mathrm{bp}$ of a nuclear intron and $65 \mathrm{bp}$ of flanking exon from the Z-chromosome CHD gene (intron b, CHD1Zb; Ellegren and Fridolfsson, 1997). PCR amplification was conducted using $1 \mu \mathrm{M}$ each of primers $3007 \mathrm{~F}$ and $3112 \mathrm{R}$, that specifically targeted the Z-chromosome (Ellegren and Fridolfsson, 1997), 1.5 U Taq DNA polymerase, $2.5 \mathrm{mM} \mathrm{MgCl}_{2}$, and $0.25 \mathrm{mM}$ each dNTP in $50 \mu$ total volume. PCR included an initial denaturing step of $94^{\circ} \mathrm{C}$ for $9 \mathrm{~min}$, followed by 35 cycles of $94^{\circ} \mathrm{C}$ for $1 \mathrm{~min}, 54^{\circ} \mathrm{C}$ for $1 \mathrm{~min}$, and $72^{\circ} \mathrm{C}$ for $1 \mathrm{~min}$, and a final elongation step at $72^{\circ} \mathrm{C}$ for $4 \mathrm{~min}$. We cleaned PCR products with a QIAquick Kit (Qiagen, Valencia, CA) and sequenced both strands using the same primers and BigDye Terminator Cycle Sequencing Kits (Applied Biosystems, Foster City, CA). Excess dye terminators were removed using ethanol precipitation, and products were sequenced with an ABI 3100 automated sequencer (Applied Biosystems, Foster City, CA).

Sequences were aligned and edited using Sequencher 4.1 (Genecodes, Ann Arbor, MI). Because females are the heterogametic sex, they contained no polymorphic sites in CHD. However, several males were heterozygous at two or more positions. To determine the gametic phase of each allele, we used allele-specific priming (Bottema et al., 1993; see also Hare and Palumbi, 1999). In short, we designed primers that were identical at all sites except the last position on the $3^{\prime}$-end, which matched one of the polymorphic sites in the template sequence 


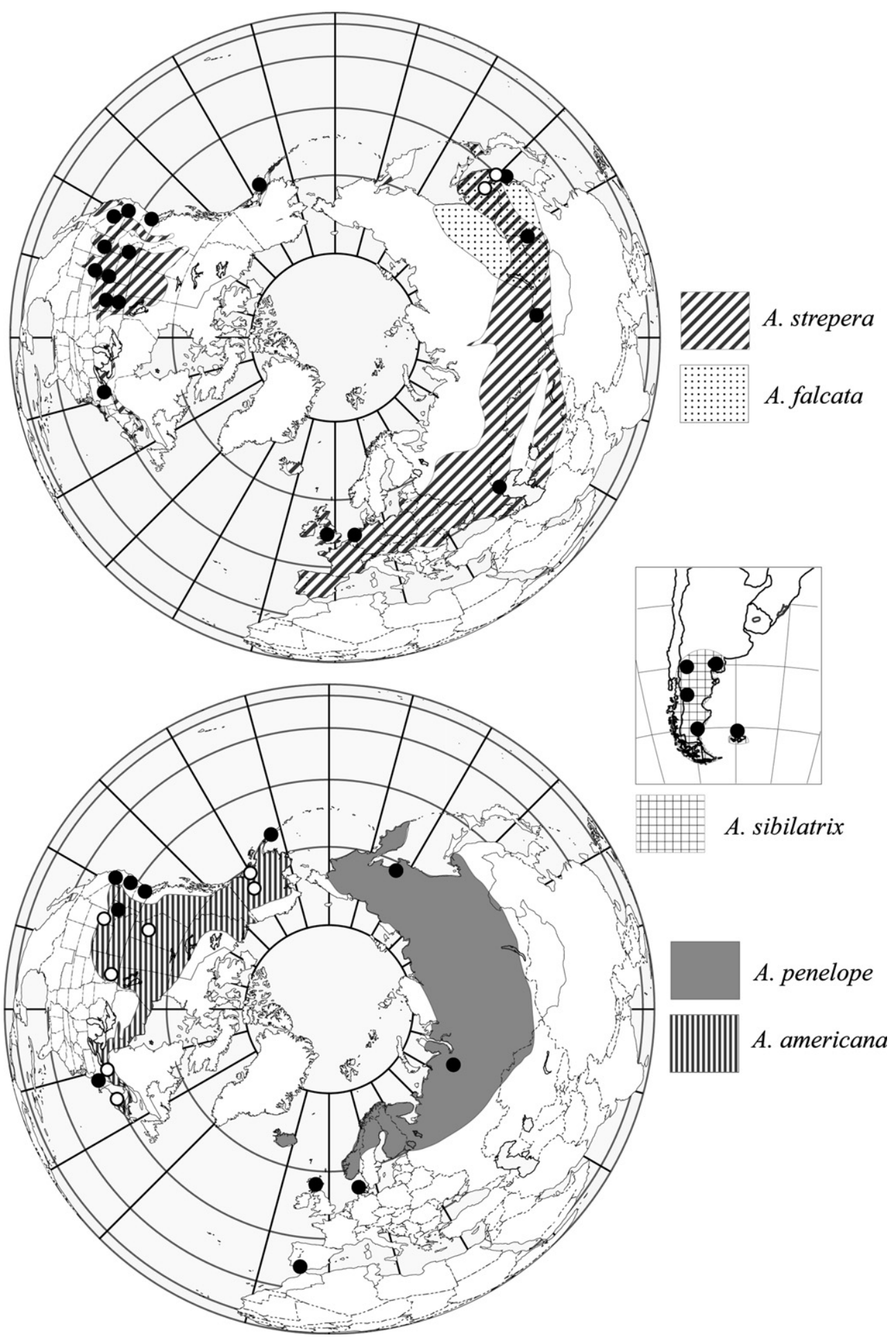

Fig. 2. Approximate breeding distributions of the five wigeons and allies (modified from LeSchack et al., 1997; Madge and Burn, 1988; Mowbray, 1999). Closed circles indicate sampling locations for A. strepera, A. sibilatrix, and A. penelope. Open circles indicate sampling locations for $A$. falcata and $A$. americana. For simplicity, only breeding distributions are illustrated, although all five species are seasonal migrants, and several individuals were sampled from migrating and over-wintering populations (see Appendix).

(Table 1). Thus, we were able to amplify and sequence both alleles individually for heterozygous males, using the PCR and sequencing protocols described above and primer-specific annealing temperatures (Table 1). One $A$. penelope and one A. falcata were not polymorphic at the primer-specific position, and for these males, we used the technique of allele subtraction to determine the gametic phase (Clark, 1990). 
Table 1

Primers used for Z-linked CHD introns

\begin{tabular}{lll}
\hline & Primer sequence & Annealing temperature $\left({ }^{\circ} \mathrm{C}\right)$ \\
\hline $\begin{array}{l}\text { Allele-specific primers } \\
\text { A. penelope }\end{array}$ & \\
3007pe.F & 5'-ACACACAGGTTCTACTCCTTCAA-3' & 48 \\
CHD281A.R & 5'-TTATTTTAGTAGACTGAAAT-3' & \\
CHD281C.R & $5^{\prime}$-TTATTTTAGTAGACTGAAAG-3' & \\
A. strepera & & 50 \\
CHD171C.F & 5'-TTGTTTCCATATCAAATAC-3' & \\
CHD171T.F & 5'-TTGTTTCCATATCAAATAT-3' & \\
CHD355.R & 5'-AGTTCCTCTGCACCAAACTTTA-3' & \\
CHD1Za & & 60 \\
CHDZa.F & 5'-CTGGACATCCTAGCAGAGTACCTA-3' \\
CHDZa.R & 5'-TCCTCAATTCCCCTTTTATTGA-3' & \\
\hline
\end{tabular}

We also sequenced 391-401 bp of CHD intron a and $36 \mathrm{bp}$ of flanking exon, for a subset of individuals (CHD1Za). We initially amplified this intron using the primers 2550F and 2718R (Ellegren and Fridolfsson, 1997; Fridolfsson and Ellegren, 1999). In females, these primers amplified the intron from the W-chromosome only, but in males, successfully amplified the Z-chromosome. Using these initial sequences, we designed internal primers specific to the Z-chromosome (Table 1). One individual representing each unique allele from $\mathrm{CHD} 1 \mathrm{Zb}$ was arbitrarily chosen for additional sequencing. Two A. strepera alleles, four $A$. penelope alleles, and two $A$. falcata alleles were not sequenced for $\mathrm{CHD} 1 \mathrm{Za}$ because amplification failed or these alleles were sampled only from heterozygotes (the gametic phase of the combined introns could not be determined).

We amplified and sequenced $658-659 \mathrm{bp}$ from domains I and II ( $5^{\prime}$-end and middle) of the mtDNA control region using the primers L78 and H774 (Sorenson and Fleischer, 1996; Sorenson et al., 1999) and the protocols described above for CHD, except that we used a $52^{\circ} \mathrm{C}$ annealing temperature (McCracken et al., 2001). Using the same protocols, we sequenced domain III (3'end) of the mtDNA control region and part of the phenylalanine tRNA ( $t$-Phe) gene for one arbitrarily chosen representative of each species using the primers L736 and H1251 (Sorenson, unpubl. data; Sorenson et al., 1999). All sequences have been deposited in GenBank (Accession Nos. AY881728-AY881966).

\subsection{Phylogenetic inferences}

We aligned CHD introns using Sequencher 4.1 (Genecodes, Ann Arbor, MI). For CHD1Zb alleles, only one 1-bp indel was observed, and the alignment was unambiguous. However, several gaps were present in CHD1Za alleles. We systematically shifted gap positions to determine which alignments required the fewest steps (see Sorenson and Payne, 2001), treating multiple-bp gaps as a single step. Ultimately, we coded the presence/ absence of four gaps that varied in size from 2 to $4 \mathrm{bp}$, and added these codes to the end of the data matrix (Prychitko and Moore, 2000). The lengths of all gaps varied between Aix sponsa and other taxa, so we defined three character states for these gaps that corresponded to length; gap length was unordered in parsimony analyses.

Because many of the mtDNA sequences varied in length among and within species due to insertions and deletions of nucleotides, and alignments were ambiguous in several regions, we aligned control region sequences using direct optimization as implemented in POY 2.7 (Gladstein and Wheeler, 2000). We included each unique haplotype (including the eight haplotypes for which we had sequence from all three domains) in this analysis and performed 100 random addition replicates (each limited to five trees), with equal weights for all changes, tree bisection and reconnection (TBR) branch swapping, and an insertion-deletion cost equal to one. Using the implied alignment generated by POY as a guide, we next optimized the alignment for the shortest tree found by POY using methods described by Sorenson and Payne (2001). Next, we systematically shifted the locations of gaps to determine whether combining some gaps as a single evolutionary event decreased the number of steps in the tree. As a result, three gaps were combined into one 8-bp deletion and two gaps were combined into a 2bp deletion. All gaps were coded as present or absent and added to the end of the data matrix (Prychitko and Moore, 2000). CHD and mtDNA alignments have been placed in TreeBase (study Accession No. S1229).

We next constructed equally weighted maximum parsimony (MP) and maximum likelihood (ML) trees for CHD and mtDNA using PAUP* 4.0b10 (Swofford, 1999). For ML estimates, we chose the most appropriate model of DNA substitution using an arbitrarily chosen MP tree and a hierarchical likelihood ratio test implemented in ModelTest 3.06 (Posada and Crandall, 1998). The initial ML tree was constructed using the chosen model (and parameter estimates) and a different MP 
starting tree. Because the number of taxa prohibited direct optimization of parameters, we re-estimated parameters based on the ML tree, and using these parameters, constructed a second ML tree. We repeated this process until tree scores and parameter values stabilized (Wilgenbusch and de Queiroz, 2000). MP and ML trees have been placed in TreeBase (study Accession No. S1229). Statistical support for MP and ML trees was evaluated by bootstrapping (Felsenstein, 1985); we conducted 1000 pseudoreplicates for the combined CHD dataset and the combined mtDNA control region dataset using a heuristic search with the TBR branchswapping algorithm. For the tree constructed from the 5 '-end of control region, we only evaluated bootstrap support for the MP tree by conducting 500 pseudoreplicates because the time required for the analyses was prohibitive.

We compared the combined mtDNA control region (domains I, II, and III) tree and the combined CHD intron (CHD1Za and CHD1Zb) tree to trees in which the topologies were constrained to agree with Livezey's (1991) morphological phylogeny and Johnson and Sorenson's (1998) mtDNA coding region phylogeny (see Fig. 1). Constraint trees were constructed in MacClade 4.0 (Maddison and Maddison, 2000). For CHD, only relationships among species were constrained. Incorporating these constraints, MP and ML trees were constructed using the methods described above. ML trees were compared using a Shimodaira-Hasegawa test with resampling-estimated log likelihood (RELL) bootstrapping and 1000 replicates (SH test, Shimodaira and Hasegawa, 1999). Because ML does not incorporate information from gaps, we also compared MP trees using a two-tailed Templeton test (Templeton, 1983). Topology tests were conducted using PAUP* $4.0 \mathrm{~b} 10$
(Swofford, 1999). For mtDNA, we only compared relationships within the wigeons and allies, but for CHD, we compared both ingroup relationships, and the relationships between the ingroup and other Anas ducks.

To evaluate how much genetic variation was partitioned among and within species, we compared $\mathrm{CHD} 1 \mathrm{Zb}$ allele frequencies among wigeons and allies using an analysis of molecular variance (AMOVA, Excoffier et al., 1992; executed in Arlequin 2.0, Schneider et al., 2000). We also calculated pairwise ФsT statistics among all pairs of species in Arlequin.

\section{Results}

\section{1. $C H D — n D N A$ phylogeny}

We sequenced a total of $116 \mathrm{CHD} 1 \mathrm{Zb}$ alleles within the wigeons and allies and found 26 unique alleles, only one of which was shared between multiple species (Fig. 3). Otherwise, alleles clustered into species-specific groupings (Fig. 3). Overall, $71.9 \%$ of the total genetic variation was explained by differences among the five species, and these differences were highly significant (AMOVA, $p<0.0001$ ). Pairwise comparisons of ФsT indicated that differences were significant among all species pairs (ФST range $=0.50-0.87, p<0.0001)$. Although $\mathrm{CHD} 1 \mathrm{Zb}$ revealed species-specific differences, relationships among species were not well-resolved. To increase the number of phylogenetically informative sites, we sequenced CHD1Za for 19 of the CHD1Zb alleles; one $A$. penelope was heterozygous for $\mathrm{CHD} 1 \mathrm{Za}$, and therefore we included 20 unique alleles in phylogenetic analyses. Combining CHD datasets for a total of 776 characters (including four coded indels; see Section 2),

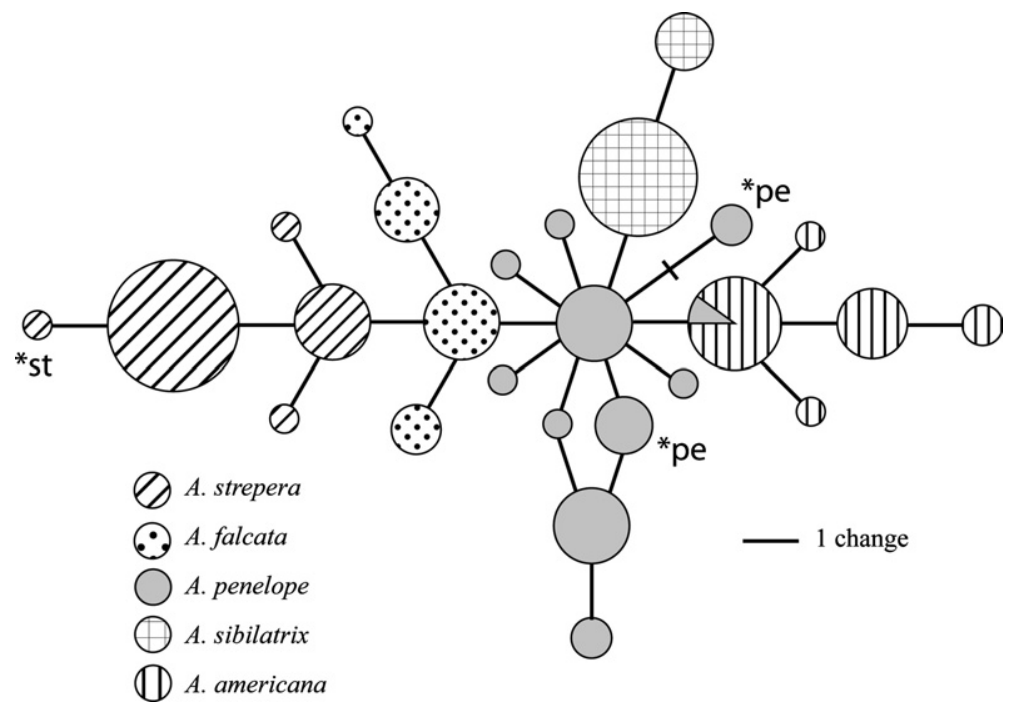

Fig. 3. Unrooted parsimony network showing the relationships among CHD1Zb alleles sampled in the five wigeon species. The areas of circles are proportional to the number of alleles sampled. *st and *pe's indicate those alleles that were sampled from A. strepera and A. penelope, respectively, that had mtDNA that disagreed with species boundaries (see text). 
we found $70(9.0 \%)$ variable sites, $21(2.7 \%)$ of which were parsimony informative, and the combined datasets provided greater phylogenetic signal for among species relationships (Fig. 4). ModelTest chose the Hasegawa, Kishino, and Yano model (HKY; Hasegawa et al., 1985) with unequal base frequencies and a transition to transversion bias $(\mathrm{ti} / \mathrm{tv}=1.3654)$.

MP and ML analyses yielded largely congruent trees (see Fig. 4). All wigeon alleles formed a clade with moderate-high bootstrap support (87\%), and A. penelope was paraphyletic to $A$. americana and $A$. sibilatrix (Fig. 4). Half of the MP trees recovered $A$. americana as monophyletic (Fig. 4A), but the remaining MP trees and the ML tree suggested that $A$. americana is paraphyletic to $A$. sibilatrix and polyphyletic with $A$. penelope (Fig. 4B). In agreement with mtDNA, $A$. strepera and $A$. falcata were recovered as sister species ( 87 and $65 \%$ bootstrap support for MP and ML analyses, respectively). $A$. falcata might be paraphyletic to A strepera, but their relationship is also consistent with reciprocal monophyly (Fig. 4). Also agreeing with mtDNA, the wigeons and allies grouped with $A$. acuta and A. carolinensis to the exclusion of $A$. clypeata and $A$. discors (the bluewinged ducks), but this relationship was not strongly supported (63 and 62\% bootstrap support for MP and ML analyses, respectively). CHD did not recover a monophyletic wigeons and allies clade, although our data also could not refute this possibility.

For maximum likelihood, the CHD nuclear intron tree did not differ significantly from trees constrained to agree with the topologies of the mtDNA or morphology trees (Table 2). However, incorporating information from gaps in MP analyses indicated that the CHD tree differed marginally from the tree constrained to agree with mtDNA, but differed significantly from one constrained to agree with morphology (Table 2). Some of this disagreement can be explained by the strongly supported paraphyly of $A$. penelope. For example, allowing $A$. penelope to be paraphyletic to A. sibilatrix and $A$. americana, but forcing a sister-relationship between $A$. sibilatrix and $A$. americana, improved the fit between CHD and mtDNA in both ML and MP comparisons (Table 2). However, allowing $A$. penelope to be paraphyletic to $A$. americana (i.e., forcing a monophyletic
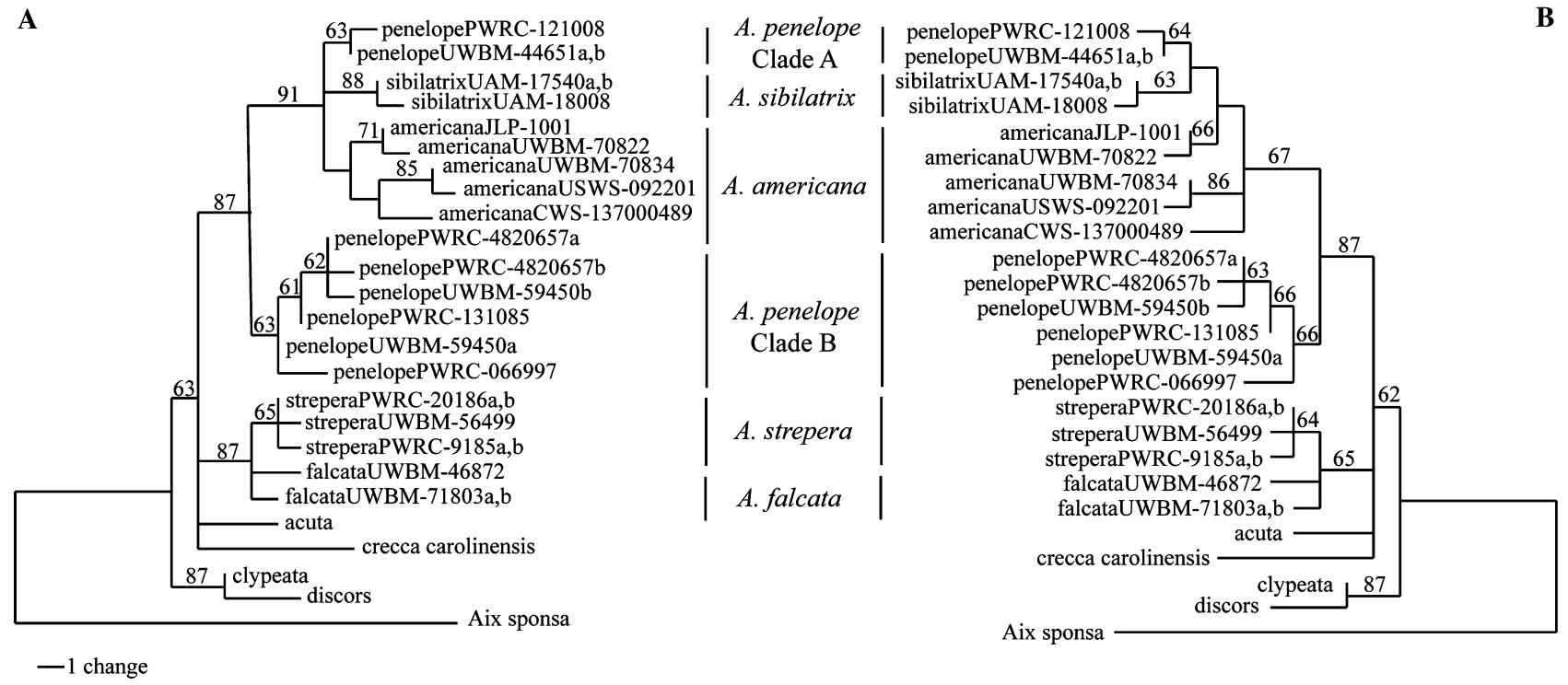

Fig. 4. Two of the six equally parsimonious trees (length $=76$ steps, $\mathrm{CI}=0.987)$ constructed from the combined $\mathrm{CHD}$ introns $(\mathrm{CHD} 1 \mathrm{Za}$ and $\mathrm{CHD} 1 \mathrm{Zb}$ ) rooted with $A$. sponsa. Half of the MP trees recovered a monophyletic A. americana (A), whereas the remaining trees and the ML tree ( $-\ln L=1523.37$ ) recovered a paraphyletic $A$. americana (B; the ML topology was identical to this tree). MP (A) and ML (B) bootstrap support that was greater than $50 \%$ is shown above branches. Alleles isolated from males, for which the gametic phase of the combined introns could be determined (i.e., they were homozygous for at least one intron), are indicated as alleles a and b.

Table 2

Comparisons between the CHD intron phylogeny and trees constrained to agree with mtDNA and morphology trees

\begin{tabular}{lllllll}
\hline Topological constraint & ML-SH test & & \multicolumn{2}{l}{ MP-Templeton test } \\
\cline { 2 - 3 } & $\ln L$ difference & $p$ & & Length difference & $z$ \\
\hline mtDNA & 9.84 & 0.26 & 3 & 1.73 & 0.08 \\
A. penelope paraphyletic & 0.65 & 0.82 & 0 & 0.0 \\
Morphology & 18.31 & 0.14 & 6 & 2.44 \\
A. penelope paraphyletic & 18.31 & 0.14 & 6 & 0.01 \\
\hline
\end{tabular}


"northern wigeon," sensu Livezey, 1991), but not $A$. sibilatrix, did not improve the fit between CHD and morphology (Table 2). Clearly, the CHD tree was more congruent with mtDNA than it was with morphology.

\section{2. $m t D N A$ phylogeny}

The size of the mtDNA control region sequence varied from 658 to $659 \mathrm{bp}$ within the wigeons and allies and yielded an alignment of 660 positions. Outgroup sequences ranged from 658 to $667 \mathrm{bp}$, and the alignment including the ingroup and outgroup was $676 \mathrm{bp}$ in length. There were 20 gaps in our alignment, which we coded as present or absent, resulting in a total of 696 characters, of which $125(18.0 \%)$ were variable and 73 $(10.5 \%)$ were parsimony informative. The best-fit ML model selected using ModelTest was the Tamura Nei (TrN; Tamura and Nei, 1993) model with invariable sites (I) and a gamma distribution $(\Gamma)$, which includes parameters for unequal base frequencies, uneven ratios of $\mathrm{C}-\mathrm{T}$ and $\mathrm{A}-\mathrm{G}$ transitions, invariant sites, and unequal rates of nucleotide substitution among sites.

Most haplotypes from each species grouped into species-specific monophyletic groups with moderate to high bootstrap support (75-99\%, Fig. 5), but three examples of mtDNA non-monophyly were observed. Two $A$. penelope shared haplotypes with $A$. americana, and were grouped within a clade containing all of the $A$. americana haplotypes (Fig. 5). One A. strepera shared a haplotype with three $A$. penelope, and this haplotype grouped within a clade containing the majority of the $A$. penelope haplotypes. These examples of paraphyly/polyphyly were observed in $100 \%$ of MP trees and the ML tree (not shown), and received moderate to high bootstrap support in parsimony analyses (75-93\%, Fig. 5). All three individuals that had mtDNA disagreeing with species boundaries had CHD alleles that clustered with other conspecifics (Fig. 3; Appendix). These examples of haplotype sharing likely resulted from interspecific hybridization rather than deep cryptic lineages or incomplete sorting of ancestral polymorphisms (see Section 4 below).

Ignoring the putative introgressed haplotypes, there was moderate to strong support for the monophyly of each species, but the relationships among the species were not well-resolved. The ML tree $(-\ln L=1966.5)$ and $100 \%$ of MP trees agreed in placing A. sibilatrix sister to $A$. americana, but this relationship was not strongly supported (54\% MP bootstrap support; Fig. 5). A. strepera and A. falcata formed a sister-group in all our analyses, and this relationship received $100 \% \mathrm{MP}$ bootstrap support. The relationship between $A$. penelope and the other species, however, was not well-supported $(<50 \%$ MP bootstrap support). Ninety-eight percent of MP trees were consistent with mtDNA coding regions suggesting that $A$. penelope is sister to the americana- sibilatrix clade (Johnson and Sorenson, 1998, 1999). Our ML analysis suggested a sister-relationship between $A$. penelope and the strepera-falcata clade (not shown). The ML tree was only 1-step longer (length $=191$ steps) than MP trees that did not include gaps.

The combined mtDNA control region sequences ( 3 '-, middle, and $5^{\prime}$-end) varied between 981 and $982 \mathrm{bp}$ for the ingroup taxa. We excluded $23 \mathrm{bp}$ of t-Phe sequence so that ingroup and outgroup sequences were completely homologous. Truncated ingroup and outgroup sequences yielded a $983 \mathrm{bp}$ alignment. After adding character codes for 29 gaps, the combined control region contained 1011 characters, $166(16.4 \%)$ of which were variable and $75(7.4 \%)$ were parsimony informative. The best-fit model selected by ModelTest was the $\operatorname{TrN}+\mathrm{I}$ (Tamura and Nei, 1993) model of evolution, which allows for unequal base frequencies, uneven ratios of $\mathrm{C}$ $\mathrm{T}$ and $\mathrm{A}-\mathrm{G}$ transitions, and invariant sites. This larger segment of control region provided additional phylogenetic signal, and this dataset better resolved the relationships within the wigeons and allies. For this dataset, two equally parsimonious trees were found that disagreed only in the relationships among the outgroup taxa, and one of these trees was identical to the ML tree $(-\ln L=2330.5$; Fig. 6). The sister taxon relationship between $A$. americana and A. sibilatrix was strongly supported in both MP and ML analyses ( 98 and $97 \%$ bootstrap support, respectively), and the placement of $A$. penelope as sister to the americana-sibilatrix clade instead of the strepera-falcata clade was moderately supported $(76 \%$ bootstrap support for both MP and $\mathrm{ML})$. The monophyly of the wigeons and allies also was supported by high bootstrap values ( 88 and $97 \%$ for MP and ML analyses, respectively). The relationships among the ingroup taxa are identical to the mtDNA coding region phylogeny of Johnson and Sorenson $(1998,1999)$. Constraining the tree topology to agree with Livezey's (1991) morphology tree required 26 additional steps (i.e., 253 steps in total), a significant difference (Templeton test, $z=4.75, p<0.0001$ ), and this tree also received a significantly worse ML-score (SH test, $\ln L$ difference = $40.25, p=0.001)$.

\section{Discussion}

\section{1. $n D N A$ phylogeny-CHD}

Relative to other nuclear introns, CHD introns showed remarkable utility as species-level phylogenetic markers. Within the wigeons and allies, we found 26 $\mathrm{CHD} 1 \mathrm{Zb}$ alleles, and only one of these was shared between species (Fig. 3). Furthermore, alleles tended to cluster into species-specific groupings, and $72 \%$ of the total genetic variation was explained by differences among species. Combining $\mathrm{CHD} 1 \mathrm{Zb}$ and $\mathrm{CHD} 1 \mathrm{Za}$ 


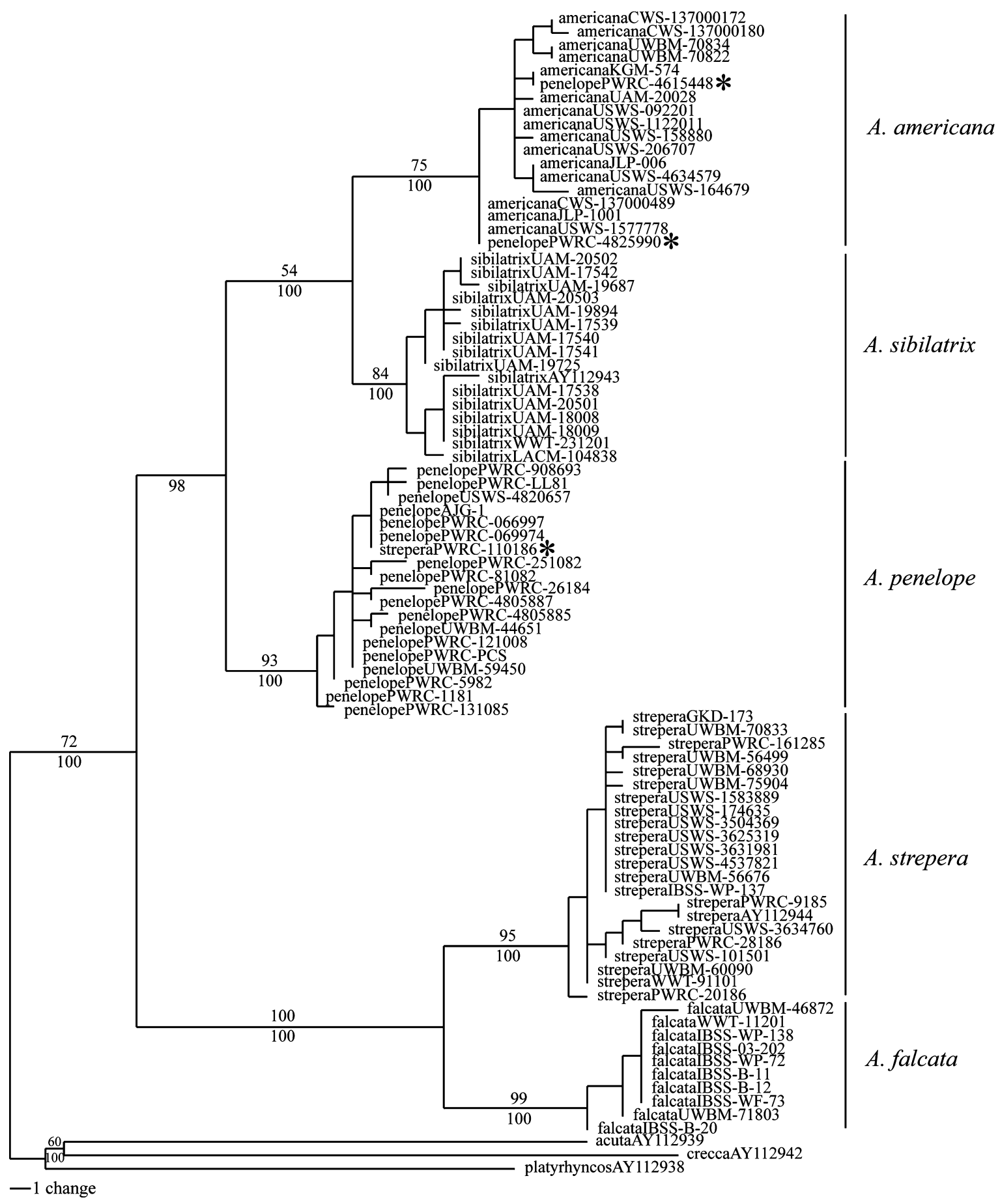

Fig. 5. Mitochondrial DNA control region phylogeny (domains I and II). MP found more than 150,000 equally parsimonious trees (length $=209$ steps, $\mathrm{CI}=0.649)$. MP bootstrap support is shown above branches $(>50 \%)$; frequency values for nodes supported by the $50 \%$ majority-rule consensus tree are shown below branches. Values are shown for deeper nodes only. Individuals that have mtDNA that disagrees with species boundaries (i.e., putative hybrids) are indicated by asterisks (*). The ML topology was similar to this tree, except that $A$. penelope was sister to the strepera-falcata clade and relationships among individuals within taxa varied.

provided strong phylogenetic signal: four of the five species were consistent with monophyletic clades, several nodes were supported by moderate to high bootstrap support, and MP trees received a high consistency index $(\mathrm{CI}=0.986$, Fig. 4). In agreement with both mtDNA (Johnson and Sorenson, 1998, 1999) and morphology
(Livezey, 1991), CHD resolved a monophyletic group consisting of the three wigeon species, and this node received high bootstrap support in both MP and ML analyses (Fig. 4). However, CHD did not recover a monophyletic clade consisting of the five wigeons and allies, nor a sister-relationship between $A$. crecca and $A$. 


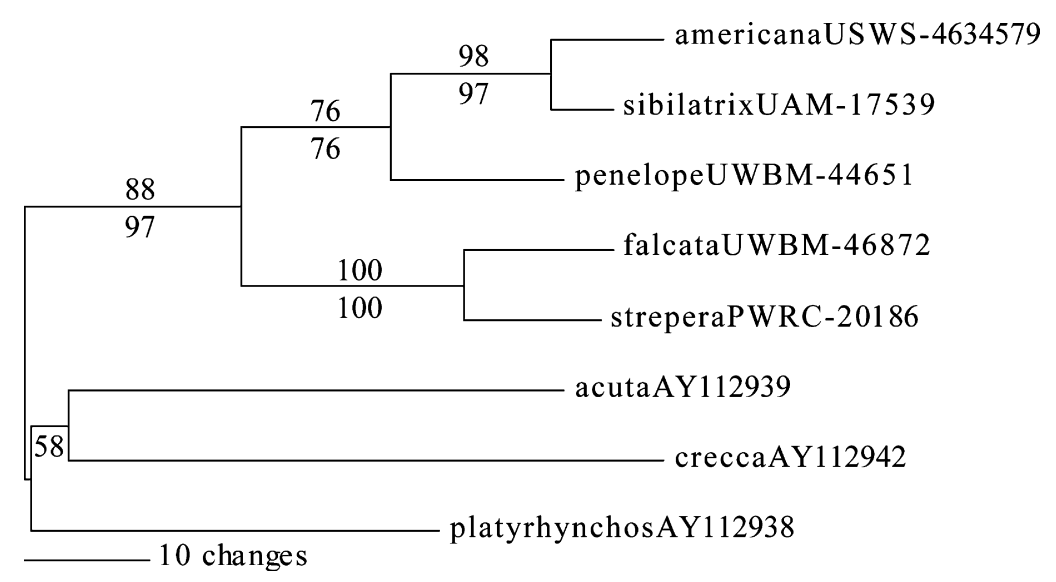

Fig. 6. Mitochondrial DNA control region phylogeny (domains I, II, and III). MP found two equally parsimonious that only differed in the relationships among outgroup taxa (length $=227$ steps, $\mathrm{CI}=0.79$ ). The topology of the $\mathrm{ML}$ tree was identical to the tree shown here $(-\ln L=2330.5)$. MP bootstrap values that were greater than $50 \%$ are shown above each branch; ML bootstrap values are shown below each branch.

acuta. Both of these relationships were supported by morphology and mtDNA. In addition, CHD did not resolve the relationships among the three wigeon species, because $A$. penelope was paraphyletic and support for relationships within the clade shared by the three wigeon species was low (see Fig. 4). The multi-furcating CHD tree suggests that its resolving power was low in some cases, but this power might be enhanced by sequencing additional linked introns. Sundstrom et al. (2003) sequenced five different CHD introns, and combining several of these introns could offer more characters for constructing a well-resolved gene tree.

The surprising observation that CHD alleles in most species have sorted to monophyly contrasts markedly with nuclear intron phylogenies for other groups of closely related species. Allen and Omland (2003) evaluated ornithine decarboxylase (ODC) among closely related species of the genus Icterus (New World orioles). Although ODC recovered the same three deeply divergent clades identified by mtDNA (see Omland et al., 1999), relationships among species within these clades were not well-resolved, and several species shared alleles or were polyphyletic. Johnson and Clayton (2000a) similarly found shared alleles and polyphyly among closely related Zenaida species (New World doves) using $\beta$ fibrinogen intron 7 (FIB7). The strong phylogenetic signal provided by CHD (sex-linked introns), relative to ODC and FIB7 (autosomal loci), may be attributed to the lower effective population size of Z-chromosomelinked loci, and the resulting slightly more rapid sorting rates. However, Pitra et al. (2002) found weak phylogenetic signal from homologous CHD introns, leading them to exclude CHD from phylogenetic analyses. Comparing our results with those of Pitra et al. (2002) suggests that the phylogenetic utility of CHD found in this study might not be characteristic of Z-linked-loci, but may be specific to the wigeons and allies.
The strong phylogenetic signal provided by CHD could be explained if the wigeons and allies experienced recent bottlenecks. Founder events leading to peripheral isolation (Mayr, 1942) or post-speciation bottlenecks could cause nuclear loci to sort much more rapidly. Johnson and Sorenson (1999), for example, found little biogeographic signal using their mtDNA phylogeny of Anas species, and they suggested that widespread dispersal in ducks may have promoted dispersal-driven divergence (i.e., divergence via peripheral isolation). When divergence is driven by dispersal and peripheral isolation, the original founders will carry a subset of the ancestral allelic diversity to the founded area, and genetic drift may eliminate additional alleles as a result of the subsequent small population size. Hence, dispersal-driven divergence can cause alleles to sort to monophyly rapidly. The tight clustering of species-specific CHD alleles within the wigeons and allies is expected under Johnson and Sorenson's (1999) dispersal-driven divergence hypothesis. Alternatively, strong selection on coding regions of CHD or other closely linked genes could cause these introns to sweep through the population, and hence, differences among species could become fixed rapidly (Donnelly and Tavaré, 1995). Sequencing additional nuclear loci will be useful for differentiating between these hypotheses (Galtier et al., 2000).

\subsection{Sampling multiple individuals - paraphyly/polyphyly}

Although we did not find deep cryptic lineages within species, dense sampling of each species revealed paraphyly and polyphyly within the wigeons and allies for both mtDNA and CHD. Specifically, two $A$. penelope shared mtDNA haplotypes with $A$. americana, and one $A$. strepera shared a mtDNA haplotype with three $A$. penelope (Fig. 5). These haplotypes were nested within 
well-supported clades containing all of the A. americana haplotypes and the majority of $A$. penelope haplotypes, respectively. In addition, dense sampling of individuals revealed a $\mathrm{CHD} 1 \mathrm{Zb}$ allele that was shared between $A$. americana and $A$. penelope (Fig. 3), and the combined CHD dataset clearly showed $A$. penelope to be paraphyletic to the other wigeons (Fig. 4).

Mitochondrial DNA haplotype sharing in this group probably resulted from interspecific hybridization. Compared to the shallow differences observed within clades, deeply divergent lineages separated the major clades of all species, suggesting long periods of isolation and divergence. In addition, Anas ducks are well known for their capacity to hybridize and produce fertile offspring (Johnsgard, 1960; Tubaro and Lijtmaer, 2002). A. americana and $A$. penelope regularly hybridize in the wild (Johnsgard, 1965; Mowbray, 1999; Sonobe and Usui, 1993), and A. penelope $\times$ A. strepera hybrids have also been observed (Johnsgard, 1965; LeSchack et al., 1997). The two $A$. penelope that shared mtDNA haplotypes with $A$. americana were both sampled from the west coast of North America where the two species' wintering distributions overlap (see Edgell, 1984). These two species also regularly come into contact in Eurasia during the winter (Cramp et al., 1977; Peterson et al., 1983; Sonobe and Usui, 1993). In waterfowl, pair formation occurs on the wintering grounds (Rohwer and Anderson, 1988), and range overlap in winter might facilitate hybridization.

In contrast to mtDNA, the paraphyly of $A$. penelope observed in CHD probably is better explained by ancestral polymorphism. CHD has three times the effective population size of mtDNA, and sorting to monophyly will occur much more slowly (Hudson and Turelli, 2003; Palumbi et al., 2001). Hence, ancestral polymorphisms will be retained in the population long after mtDNA has sorted to monophyly. The clustering of $A$. penelope $\mathrm{CHD} 1 \mathrm{Zb}$ alleles, the independent derivation of $A$. americana and $A$. sibilatrix alleles from an "ancestral" $A$. penelope allele (Fig. 3; see Castelloe and Templeton, 1994), and two distinct lineages of $A$. penelope in the combined CHD introns phylogeny (Fig. 4) further argues for ancestral polymorphism. Although ancestral polymorphism seems to be the better explanation of paraphyly in CHD, the possibility of interspecific hybridization cannot be ruled out.

In this study, the level of interspecific mtDNA haplotype sharing was low, but it does reinforce the point that using only one representative of each species can mislead phylogenetic inferences (Funk and Omland, 2003; Omland, 1997; Omland et al., 1999). At least in this group of ducks, two representatives would usually be sufficient to improve confidence in phylogenetic relationships, because the probability of sampling two introgressed haplotypes is low. In contrast, Kulikova et al. (2004) sampled 22 individuals of Anas zonorhyncha (eastern spot-billed duck) and found two common clades of mtDNA haplotypes. Kulikova et al. (2004) concluded that the single haplotype sequenced by Johnson and Sorenson $(1998,1999)$ resulted from introgression, and that the previously unidentified clade originally belonged to A. zonorhyncha. These results have challenged former inferences of phylogenetic relationships among mallard species. Similarly, in this study, one representative of CHD would not have revealed the paraphyly of $A$. penelope, and conclusions regarding the relationships among the three wigeon species would vary depending on which clade of $A$. penelope was sampled. Sampling multiple individuals of each taxon for phylogenetic analyses will be most important when interspecific hybridization is common and when linkage groups, especially nuclear introns, may have had an insufficient amount of time to sort to monophyly (see Funk and Omland, 2003).

\subsection{DNA, morphology, and biogeography}

In this study, phylogenies constructed from DNA and morphology are largely incongruent (see also Johnson and Sorenson, 1999), whereas the mtDNA and CHD trees are congruent. mtDNA recovered $A$. americana as sister to $A$. sibilatrix, with this relationship receiving high bootstrap support from both coding regions and the combined control region datasets $(100$ and $98 \%$, respectively; Johnson and Sorenson, 1998, 1999; Fig. 6, this study). In contrast, all 157 morphological characters scored by Livezey (1991) were shared between A. americana and $A$. penelope, whereas $A$. sibilatrix differed from these two species by seven characters, six of which were shared with $A$. strepera and A. falcata. Behavioral displays, including courtship displays and family rituals, also indicate that $A$. americana is phenotypically more similar to A. penelope than to A. sibilatrix (Brewer, 1997; Johnsgard, 1965). Although CHD was not conclusive, the basal position of an exclusively $A$. penelope clade, and the ancestral position of an A. penelope $\mathrm{CHD} 1 \mathrm{Zb}$ allele, strongly argues against an earlier divergence of $A$. sibilatrix, but argues for a recent derivation of $A$. sibilatrix from a northern ancestor (also see Johnson and Sorenson, 1999; Livezey, 1991). These observations raise an interesting question; why is there such profound disagreement between phenotype and genotype among the wigeon species?

Interestingly, a second clade of Anas ducks has a biogeographic pattern and a conflict between mtDNA and morphology that is analogous to that found in the wigeons. The green-wing teal (Anas crecca) includes two subspecies from the northern hemisphere, $A$. c. crecca (Eurasian common teal) and A. c. carolinensis (North American green-winged teal) that are almost identical morphologically (Livezey, 1991). However, mtDNA indicates that $A$. c. carolinensis is sister to the South 
American species-complex, A. flavirostris (speckled teal; Johnson and Sorenson, 1998, 1999), but these taxa differ substantially in morphology (Livezey, 1991). These congruent patterns between wigeons and green-winged teal possibly resulted from selective pressures that differed between southern and northern hemispheres and caused rapid divergence in phenotypic characters following the colonization of South America from North America (see Johnson, 1999; Johnson et al., 1999). Hence, phenotypes may have accumulated diagnostic differences much more rapidly than DNA (see also Cunningham et al., 1992; Kondo et al., 2004). The parallel discordance between morphology and DNA in the wigeons and the greenwinged teal offers an exciting opportunity to investigate potential interactions between peripheral isolation and disruptive selection during speciation, using comparative phylogeography.

There also exists disagreement between phenotype and DNA in the placement of $A$. falcata. Morphology and behavior both suggest that $A$. falcata is an evolutionary link between the wigeon species and $A$. strepera, whereas $A$. strepera is intermediate between the wigeon species (including A. falcata) and other Anas species (Johnsgard, 1965; Livezey, 1991). However, mtDNA strongly favors $A$. falcata as sister to A. strepera, not the wigeon species (Johnson and Sorenson, 1998, 1999; Figs. 5 and 6, this study), and CHD corroborated this relationship (Fig. 4). Again, why is there strong disagreement between phenotype and genotype? It seems likely that some of this disagreement within Anas ducks might be explained by convergence or reversals in phenotypic characters (e.g., McCracken et al., 1999; Omland and Lanyon, 2000), but ancient introgression of DNA from close relatives also might have played a role (Ballard and Whitlock, 2004).

\section{Conclusions}

We found CHD introns to have strong phylogenetic potential compared to other nuclear introns. However, it is unclear whether this phylogenetic signal is best explained by: (1) the hypothesized faster sorting rate of Z-linked loci relative to autosomal loci, (2) extreme bottlenecks in this group of ducks, perhaps coincident with dispersal-driven divergence, or (3) strong selection on closely linked loci. Regardless, the phylogenetic utility of CHD introns should be evaluated in other taxa for which a well-resolved gene tree is desired. Also, within this group of ducks, there is strong disagreement between phenotype and DNA in the relationships among the wigeons and allies, but the evolutionary implications of this conflict are unclear. To examine this conflict in more detail, a comparison between morphology, mtDNA, and additional nuclear DNA is needed.

\section{Acknowledgments}

We thank the following people and institutions/organizations for providing tissue samples and loans: Sharon Birks, Burke Museum of Natural History and Culture, University of Washington; Paul Padding and Woody Martin, Patuxant Wildlife Research Center, USA; Ruth Cromie, Wildfowl and Wetlands Trust, UK; Norm North, Canadian Wildlife Service, Canada; Kimball L. Garrett, Natural History Museum of Los Angeles County; and Andrew J. Green and Violeta Muñoz, Estaciõn Biológica de Doñana, Spain. We would also like to thank the following organizations for logistical support: Migratory Bird Permit Office, US Fish and Wildlife Service; Animal and Plant Health Inspection Service, US Department of Agriculture; North Dakota Game and Fish Department; Alaska Department of Fish and Game; Falkland Islands Government; and the following governmental agencies of Argentina: Secretaría del Estado de Producción Río Negro; Centro de Ecología Aplicada y Dirección Provincial Recursos Faunisticos y Areas Naturales Protegidas Neuquén; Dirección de Fauna Santa Cruz; Dirección de Fauna Silvestre, Secretaría de Ambiente y Desarrollo Sustentable de la República Argentina; and Ministerio de la Producción Chubut. We thank the following people for their assistance in the laboratory and field: Kairav Doshi, Elizabeth M. Humphries, Roland Y. Cheung, Raúl Cardón, Raúl Clarke, Adrian Contreras, Sergio Goldfeder, Alejandro Gonzalez, Antony Lancaster, Daniel Ramadori, Alejandro del Valle, Elizabeth Loos, Kristen Chodacheck, and Nathan Pfost. Beatrice Kondo and an anonymous reviewer provided valuable comments on the manuscript. This study was funded by grants from Delta Waterfowl Foundation to J.L.P., from the Institute of Arctic Biology at the University of Alaska Fairbanks, Alaska, EPSCoR (NSF EPS-0092040) to K.G.M., and from the Frank M. Chapman Fund at the American Museum of Natural History to R.E.W. 


\section{Appendix}

Collection information and identification of CHD alleles for all individuals of wigeons and allies included in this study

\begin{tabular}{|c|c|c|c|c|c|}
\hline Species & Identification number ${ }^{\mathrm{a}}$ & Country: state or province & Season $^{b}$ & $\mathrm{CHD}$ alleles ${ }^{\mathrm{c}, \mathrm{d}}$ & Tissue type \\
\hline Anas strepera & PWRC-161285 & Netherlands & NB & st2, st2 & Muscle \\
\hline A. strepera & PWRC-9185 & Netherlands & NB & $\mathrm{st} 2, \mathrm{st} 2$ & Muscle \\
\hline A. strepera & PWRC-20186 & Netherlands & NB & st3, st3 & Muscle \\
\hline A. strepera & PWRC-28186 & Netherlands & NB & $?$ & Muscle \\
\hline A. strepera & PWRC-110186 & Netherlands & NB & st1 & Muscle \\
\hline A. strepera & UWBM-56499 & Russia: Astrakhanskaya Oblast' & $\mathrm{B}$ & st4 & Muscle \\
\hline A. strepera & UWBM-56676 & Russia: Astrakhanskaya Oblast' & B & st1, st1 & Muscle \\
\hline A. strepera & UWBM-60090 & Mongolia: Donrod Aymag & B & st3 & Muscle \\
\hline A. strepera & UWBM-75904 & Russia: Respublika Tyva & B & st1, st5 & Muscle \\
\hline A. strepera & IBSS-WP-137 & Russia: Primorskiy Kray & NB & st3, st3 & Muscle \\
\hline A. strepera & WWT-91101 & United Kingdom & NB & st 2, st 2 & Feathers \\
\hline A. strepera & UWBM-68930 & USA: California & $\mathrm{B}$ & st2, st2 & Muscle \\
\hline A. strepera & GKD-173 & USA: Washington & NB & st2 & Muscle \\
\hline A. strepera & UWBM-70833 & USA: Utah & B & st2 & Muscle \\
\hline A. strepera & USWS-3631981 & USA: North Dakota & $\mathrm{B}$ & st2, st2 & Muscle \\
\hline A. strepera & USWS-3504369 & USA: Colorado & B & st2 & Muscle \\
\hline A. strepera & USWS-4537821 & USA: Nevada & B & st 2, st 2 & Muscle \\
\hline A. strepera & USWS-1746935 & USA: New York & B & st2 & Muscle \\
\hline A. strepera & USWS-3625319 & USA: South Dakota & B & st2 & Muscle \\
\hline A. strepera & USWS-1583889 & USA: Wyoming & B & st2, st2 & Muscle \\
\hline A. strepera & USWS-101501 & USA: Alaska & B & st3 & Muscle \\
\hline A. strepera & USWS-3634760 & USA: Montana & B & st2, st3 & Muscle \\
\hline A. falcata & UWBM-71803 & Russia: Primorskiy Kray & B & fa 3, fa 3 & Muscle \\
\hline A. falcata & UWBM-46872 & Russia: Khabarovkiy Kray & B & fal & Muscle \\
\hline A. falcata & WWT-11201 & United Kingdom: captivity & NA & fal & Feathers \\
\hline A. falcata & IBSS-B-20 & Russia: Primorskiy Kray & NB & fa3, fa3 & Muscle \\
\hline A. falcata & IBSS-WP-138 & Russia: Primorskiy Kray & NB & fa3 & Muscle \\
\hline A. falcata & IBSS-03-202 & Russia: Primorskiy Kray & NB & $\mathrm{fa} 1, \mathrm{fa} 2$ & Muscle \\
\hline A. falcata & IBSS-WP-72 & Russia: Primorskiy Kray & NB & fal & Muscle \\
\hline A. falcata & IBSS-B-11 & Russia: Primorskiy Kray & NB & $\mathrm{fa} 2, \mathrm{fa} 4$ & Muscle \\
\hline A. falcata & IBSS-B-12 & Russia: Primorskiy Kray & NB & fal, fal & Muscle \\
\hline A. falcata & IBSS-WF-73 & Russia: Primorskiy Kray & NB & $\mathrm{fa} 2, \mathrm{fa} 2$ & Muscle \\
\hline A. sibilatrix & UAM-18008 & East Falkland Islands & $\mathrm{B}$ & si2 & Blood \\
\hline A. sibilatrix & UAM-18009 & East Falkland Islands & B & si2 & Blood \\
\hline A. sibilatrix & UAM-17540 & Argentina: Rio Negro & B & sil, sil & Muscle \\
\hline A. sibilatrix & UAM-17539 & Argentina: Rio Negro & $\mathrm{B}$ & sil, sil & Muscle \\
\hline A. sibilatrix & UAM-17542 & Argentina: Rio Negro & B & sil, sil & Muscle \\
\hline A. sibilatrix & UAM-17541 & Argentina: Rio Negro & B & si2 & Muscle \\
\hline A. sibilatrix & UAM-17538 & Argentina: Rio Negro & B & sil & Muscle \\
\hline A. sibilatrix & UAM-20501 & Argentina: Neuquen & B & sil & Muscle \\
\hline A. sibilatrix & UAM-20502 & Argentina: Neuquen & B & sil, sil & Muscle \\
\hline A. sibilatrix & LACM-104838 & Argentina: Neuquen & B & sil, sil & Muscle \\
\hline A. sibilatrix & UAM-20503 & Argentina: Chubut & B & sil & Muscle \\
\hline A. sibilatrix & UAM-19894 & Argentina: Chubut & B & sil & Muscle \\
\hline A. sibilatrix & UAM-19687 & Argentina: Santa Cruz & B & si2 & Muscle \\
\hline A. sibilatrix & UAM-19725 & Argentina: Santa Cruz & B & sil & Muscle \\
\hline A. sibilatrix & WWT-231201 & United Kingdom: captivity & NA & sil, sil & Feathers \\
\hline A. americana & UAM-20028 & USA: Alaska & NB & ampe1, am3 & Muscle \\
\hline A. americana & KGM-574 & USA: Alaska & B & ampel & Muscle \\
\hline A. americana & UWBM-70822 & USA: Utah & B & am4 & Muscle \\
\hline A. americana & UWBM-70834 & USA: Utah & B & ampe1 & Muscle \\
\hline A. americana & CWS-137000172 & Canada: Quebec & B & ampe1 & Muscle \\
\hline A. americana & CWS-137000180 & Canada: Quebec & $\mathrm{B}$ & ampe1, am3 & Muscle \\
\hline A. americana & CWS-137000489 & Canada: Alberta & B & aml & Muscle \\
\hline A. americana & JLP-006 & USA: North Dakota & B & am4 & Foot-webbing \\
\hline A. americana & USWS-1122011 & USA: Maine & NB & ampe1, am3 & Muscle \\
\hline A. americana & USWS-092201 & USA: Alaska & NB & am2 & Muscle \\
\hline A. americana & USWS-206707 & USA: North Dakota & B & ampel, ampel & Muscle \\
\hline A. americana & USWS-158880 & USA: Alaska & NB & ampel & Muscle \\
\hline A. americana & USWS-164679 & USA: Alaska & NB & am3 & Muscle \\
\hline
\end{tabular}


Appendix (continued)

\begin{tabular}{|c|c|c|c|c|c|}
\hline Species & Identification number $^{\mathrm{a}}$ & Country: state or province & Season $^{\mathrm{b}}$ & CHD alleles ${ }^{\mathrm{c}, \mathrm{d}}$ & Tissue type \\
\hline A. americana & USWS-1577778 & USA: New York & $\mathrm{B}$ & am3 & Muscle \\
\hline A. americana & JLP-1001 & USA: North Dakota & B & $\mathrm{am} 3$ & Foot-webbing \\
\hline A. americana & USWS-4634579 & USA: Alaska & B & $?$ & Muscle \\
\hline A. penelope & UWBM-59450 & $\begin{array}{l}\text { Russia: Yamalo-Nenetskiy } \\
\text { Avtonomnyy Okrug }\end{array}$ & B & pe1, pe10 & Muscle \\
\hline A. penelope & UWBM-44651 & Russia: Magadanskaya Oblast & B & pe1, pe1 & Muscle \\
\hline A. penelope & PWRC-LL81 & United Kingdom: Scotland & NB & pe 5 & Muscle \\
\hline A. penelope & PWRC-1181 & United Kingdom: Scotland & NB & pe1, pe8 & Muscle \\
\hline A. penelope & PWRC-251082 & Denmark & NB & pe3, pe9 & Muscle \\
\hline A. penelope & PWRC-26184 & Denmark & NB & pe9, pe10 & Muscle \\
\hline A. penelope & PWRC-81082 & Denmark & NB & pe9 & Muscle \\
\hline A. penelope & PWRC-5982 & Denmark & NB & pe1 & Muscle \\
\hline A. penelope & PWRC-131085 & Denmark & NB & pe6 & Muscle \\
\hline A. penelope & AJG-1 & Spain & $\mathrm{B}$ & pe6 & Intestine \\
\hline A. penelope & PWRC-4820657 & USA: Washington & NB & pe9, pe9 & Muscle \\
\hline A. penelope & PWRC-908693 & USA: Washington & NB & pe1, pe2 & Muscle \\
\hline A. penelope & PWRC-066997 & USA: Oregon & NB & pe8 & Muscle \\
\hline A. penelope & PWRC-069974 & USA: Oregon & NB & pe1 & Muscle \\
\hline A. penelope & PWRC-4615448 & USA: California & NB & pe6 & Muscle \\
\hline A. penelope & PWRC-121008 & USA: California & NB & pe7 & Muscle \\
\hline A. penelope & PWRC-4825990 & USA: Idaho & NB & pe 8 , pe10 & Muscle \\
\hline A. penelope & PWRC-PCS & USA: Massachusetts & NB & pe9 & Muscle \\
\hline A. penelope & PWRC-4805885 & USA: Alaska & NB & ampe1, pe9 & Muscle \\
\hline A. penelope & PWRC-4805887 & USA: Alaska & NB & pe4, pe6 & Muscle \\
\hline
\end{tabular}

${ }^{a}$ Museums are abbreviated as follows for voucher specimens: UWBM, University of Washington Burke Museum; UAM, University of Alaska Museum; LACM, Natural History Museum of Los Angeles County; IBSS (Institute of Biology and Soil Sciences, Russian Academy of Sciences); KGM, collected by K.G. McCracken (UAF); GKD, collected by G.K. Davis (UWBM). Abbreviations for nonvouchered specimens are as follows: PWRC, Patuxent Wildlife Research Center; USWS, United States Wing Survey; WWT, Wildfowl \& Wetlands Trust; CWS, Canadian Wing Survey; AJG, collected by A.J. Green; JLP, collected by J.L. Peters.

${ }^{\mathrm{b}}$ Season in which individuals were sampled. B, breeding season; NB, non-breeding season; and NA, not applicable (sampled in captivity).

c Two CHD alleles indicate a male individual, one allele indicates a female, and a ? indicates that CHD was not sequenced for that individual.

${ }^{d}$ Key to CHD alleles (also see Fig. 3).

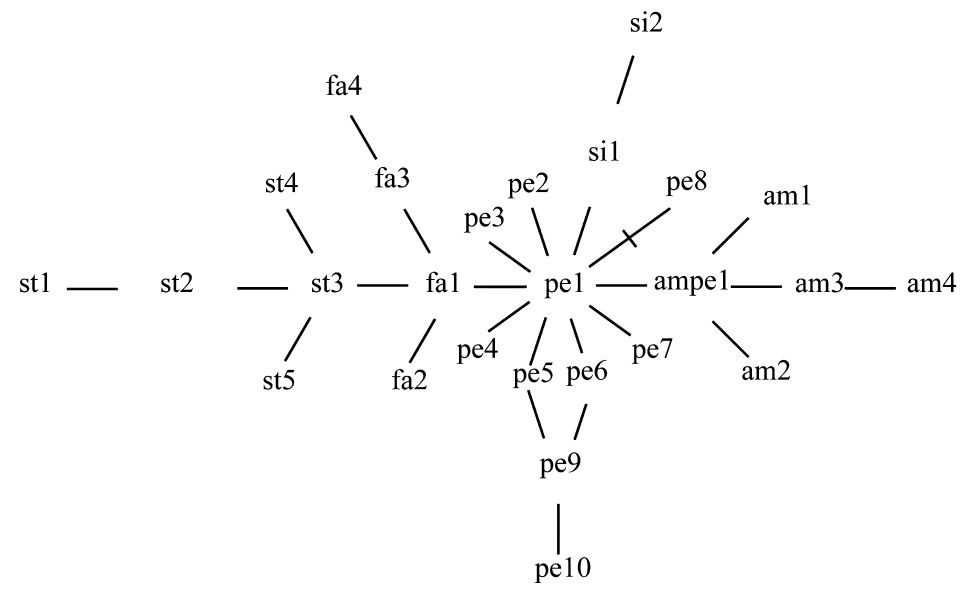

\section{References}

Allen, E.S., Omland, K.E., 2003. Phylogeny of novel intron supports plumage convergence in orioles (Icterus). Auk 120,961-969.

Armstrong, M.H., Braun, E.L., Kimball, R.T., 2001. Phylogenetic utility of avian ovomucoid intron G: a comparison of nuclear and mitochondrial phylogenies in Galliformes. Auk 118, 799804.

Avise, J.C., Arnold, J., Ball, R., Bermingham, E., Lamb, T., Neigel, J.E., Reeb, C.A., Saunders, N.C., 1987. Intraspecific phylogeography: the mitochondrial DNA bridge between population genetics and systematics. Annu. Rev. Ecol. Syst. 18, 489-522.
Avise, J.C., Ankney, C.D., Nelson, W.S., 1990. Mitochondrial gene trees and the evolutionary relationship between mallard and black ducks. Evolution 44, 1109-1119.

Avise, J.C., Alisauskas, R.T., Nelson, W.S., Ankney, C.D., 1992. Matriarchal population genetic structure in an avian species with female natal philopatry. Evolution 46, 1084-1096.

Avise, J.C., 2000. Phylogeography: The History and Formation of Species. Harvard University Press, Cambridge, MA.

Ballard, J.W.O., Whitlock, M.C., 2004. The incomplete natural history of mitochondria. Mol. Ecol. 13, 729-744.

Barker, F.K., 2004. Monophyly and relationships of wrens (Aves: Troglodytidae): a congruence analysis of heterogeneous mitochon- 
drial and nuclear DNA sequence data. Mol. Phylogenet. Evol. 31, 486-504.

Bottema, C.D.K., Sarkar, G., Cassady, J.D., Li, S., Dutton, C.M., Sommer, S.S., 1993. Polymerase chain reaction amplification of specific alleles: general method of rapidly detecting mutations, polymorphisms, and haplotypes. Methods Enzymol. 218, 388-402.

Brewer, G.L., 1997. Displays and breeding behaviour of the Chiloe Wigeon Anas sibilatrix.. Wildfowl 47, 97-125.

Brown, W.M., George, M.J., Wilson, A.C., 1979. Rapid evolution of animal mitochondrial DNA. Proc. Natl. Acad. Sci. USA 76, 19671971.

Castelloe, J., Templeton, A.R., 1994. Root probabilities for intraspecific gene trees under neutral coalescent theory. Mol. Phylogenet. Evol. 3, 102-113.

Clark, A.G., 1990. Inference of haplotypes from PCR-amplified samples of diploid populations. Mol. Biol. Evol. 7, 111-122.

Cramp, S., Simmons, K.E.L., Ferguson-Lees, I.J., Gillmor, R., Hollom, P.A.D., Hudson, R., Nicholson, E.M., Ogilvie, M.A., Olney, P.J.S., Voous, K.H., Wattel, J., 1977. Handbook of the Birds of Europe, the Middle East, and North Africa: The Birds of the Western Palearctic. Oxford University Press, Oxford.

Cunningham, C.W., Blackstone, N.W., Buss, L.W., 1992. Evolution of king crabs from hermit crab ancestors. Nature 355, 539-542.

DeBry, R.W., Seshadri, S., 2001. Nuclear intron sequences for phylogenetics of closely related mammals: an example using the phylogeny of Mus. J. Mammal. 82, 280-288.

Donne-Gousse, C., Laudet, V., Hanni, C., 2002. A molecular phylogeny of anseriformes based on mitochondrial DNA analysis. Mol. Phylogenet. Evol. 23, 339-356.

Donnelly, P., Tavaré, S., 1995. Coalescents and genealogical structure under neutrality. Annu. Rev. Genet. 29, 401-421.

Edgell, M.C.R., 1984. Trans-hemispheric movements of Holarctic Anatidae: the Eurasian wigeon (Anas penelope L.) in North America. J. Biogeogr. 11, 27-39.

Ellegren, H., Fridolfsson, A.-K., 1997. Male-driven evolution of DNA sequences in birds. Nat. Genet. 17, 182-184.

Excoffier, L., Smouse, P.E., Quattro, J.M., 1992. Analysis of molecular variance inferred from metric distances among DNA haplotypes: application to human mitochondrial DNA restriction data. Genetics 131, 479-491.

Felsenstein, J., 1985. Confidence limits on phylogenies: an approach using the bootstrap. Evolution 39, 783-791.

Fridolfsson, A.-K., Ellegren, H., 1999. A simple and universal method for molecular sexing of non-ratite birds. J. Avian Biol. 30, 116-121.

Fridolfsson, A.-K., Ellegren, H., 2000. Molecular evolution of the CHD1 avian genes on the $\mathrm{Z}$ and $\mathrm{W}$ sex chromosomes. Genetics 155 , 1903-1912.

Funk, D.J., Omland, K.E., 2003. Species-level paraphyly and polyphyly: frequency, causes and consequences with insights from animal mitochondrial DNA. Annu. Rev. Ecol. Evol. Syst. 22, 397-422.

Galtier, N., Depaulis, F., Barton, N.H., 2000. Detecting bottlenecks and selective sweeps from DNA sequence polymorphism. Genetics 155, 981-987.

Gladstein, D., Wheeler, W., 2000. POY: Phylogeny Reconstruction via Direct Optimization of DNA Data, version 2.0. American Museum of Natural History, New York, New York.

Hare, M.P., Palumbi, S.R., 1999. The accuracy of heterozygous base calling from diploid sequence and resolution of haplotypes using allele-specific sequencing. Mol. Ecol. 8, 1750-1752.

Hare, M., 2001. Prospects for nuclear gene phylogeography. Trends Ecol. Evol. 16, 700-706.

Hasegawa, M., Kishino, H., Yano, T., 1985. Dating the human-ape splitting by a molecular clock of mitochondrial DNA. J. Mol. Evol. $22,160-174$.

Hudson, R.R., Turelli, M., 2003. Stochasticity overrules the three-times rule: genetic drift, genetic draft, and coalescence times for nuclear loci versus mitochondrial DNA. Evolution 57, 182-190.
Johnsgard, P.A., 1960. Hybridization in the Anatidae and its taxonomic implications. Condor 62, 25-33.

Johnsgard, P.A., 1965. A Handbook of Waterfowl Behavior. Cornell University Press, Ithaca, New York.

Johnson, K.P., Sorenson, M.D., 1998. Comparing molecular evolution in two mitochondrial protein coding genes (cytochrome $\mathrm{b}$ and ND2) in the dabbling ducks (Tribe: Anatini). Mol. Phylogenet. Evol. 10, 82-94.

Johnson, K.P., 1999. The evolution of bill coloration and plumage dimorphism supports the transference hypothesis in dabbling ducks. Behav. Ecol. 10, 63-67.

Johnson, K.P., McKinney, F., Sorenson, M.D., 1999. Phylogenetic constraint on male parental care in the dabbling ducks. Proc. R. Soc. Lond. B 266, 759-763.

Johnson, K.P., Sorenson, M.D., 1999. Phylogeny and biogeography of dabbling ducks (Genus: Anas): a comparison of molecular and morphological evidence. Auk 116, 792-805.

Johnson, K.P., Clayton, D.H., 2000a. A molecular phylogeny of the dove genus Zenaida: Mitochondrial and nuclear DNA sequences. Condor 102, 864-870.

Johnson, K.P., Clayton, D.H., 2000b. Nuclear and mitochondrial genes contain similar phylogenetic signal for pigeons and doves (Aves: Columbiformes). Mol. Phylogenet. Evol. 14, 141-151.

Kahn, N.W., Quinn, T.W., 1999. Male-driven evolution among eoaves? A test of the replicative division hypothesis in a heterogametic female (ZW) system. J. Mol. Evol. 49, 750-759.

Kessler, L.G., Avise, J.C., 1984. Systematic relationships among waterfowl (Anatidae) inferred from restriction endonuclease analysis of mitochondrial DNA. Syst. Zool. 33, 370-380.

Kondo, B., Baker, J.M., Omland, K.E., 2004. Recent speciation between Baltimore oriole and black-backed oriole. Condor 106, 674-680.

Kulikova, I.V., Zhuravlev, Y.N., McCracken, K.G., 2004. Asymmetric hybridization and sex-biased gene flow between eastern spot-billed ducks and mallards in the Russian Far East. Auk 121, 930-949.

LeSchack, C.R., McKnight, S.K., Hepp, G.R., 1997. Gadwall (Anas strepera). In: Poole, A., Gill, F. (Eds.). The Birds of North America, No. 283, The Academy of Natural Sciences and The American Ornithologists Union, Philadelphia, PA, Washington, DC, pp. 1-28.

Livezey, B.C., 1991. A phylogenetic analysis and classification of recent dabbling ducks (Tribe Anatini) based on comparative morphology. Auk 108, 471-508.

Maddison, D.R., Maddison, W.P., 2000. MacClade 4. Sinauer Associates Inc, Sunderland, MA.

Madge, S., Burn, H., 1988. Waterfowl: An Identification Guide to the Ducks, Geese, and Swans of the World. Houghton Mifflin Company, New York.

Mayr, E., 1942. Systematics and the Origin of Species. Belknap Press, Cambridge, MA.

McCracken, K.G., Harshman, J., McClellan, D., Afton, A.D., 1999. Data set incongruence and correlated character evolution: an example of functional convergence in the hind-limbs of stifftail diving ducks. Syst. Biol. 48, 683-714.

McCracken, K.G., Johnson, W.P., Sheldon, F.H., 2001. Molecular population genetics, phylogeography, and conservation biology of the Mottled Duck (Anas fulvigula). Conserv. Genet. 2, 87-102.

Montell, H., Fridolfsson, A.-K., Ellegren, H., 2001. Contrasting levels of nucleotide diversity on the avian $\mathrm{Z}$ and $\mathrm{W}$ sex chromosomes. Mol. Biol. Evol. 18, 2010-2016.

Moore, W.S., 1995. Inferring phylogenies from mtDNA variation: mitochondrial-gene trees versus nuclear-gene trees. Evolution 49, 718-726.

Moritz, C., Dowling, T.E., Brown, W.M., 1987. Evolution of animal mitochondrial DNA: relevance for population biology and systematics. Annu. Rev. Ecol. Syst. 18, 269-292.

Mowbray, T., 1999. American Wigeon (Anas americana). In: The Birds of North America, No. 401. The Academy of Natural Sciences and The American Ornithologists' Union, Philadelphia, PA and Washington, DC, pp. 1-32. 
Omland, K.E., 1994. Character congruence between a molecular and a morphological phylogeny for dabbling ducks (Anas). Syst. Biol. 43, 369-386.

Omland, K.E., 1997. Examining two standard assumptions of ancestral reconstructions: repeated loss of dichromatism in dabbling ducks (Anatini). Evolution 51, 1636-1646.

Omland, K.E., Lanyon, S.M., Fritz, S.J., 1999. A molecular phylogeny of the New World orioles (Icterus): the importance of dense taxon sampling. Mol. Phylogenet. Evol. 12, 224-239.

Omland, K.E., Tarr, C.L., Boarman, W.I., Marzluff, J.M., Fleischer, R.C., 2000. Cryptic genetic variation and paraphyly in ravens. Proc. R. Soc. Lond. B 267, 2475-2482.

Omland, K.E., Lanyon, S.M., 2000. Reconstructing plumage evolution in orioles (Icterus): repeated convergence and reversal in patterns. Evolution 54, 2119-2133.

Palumbi, S.R., Cipriano, F., Hare, M.P., 2001. Predicting nuclear gene coalescence from mitochondrial data: the three-times rule. Evolution 55, 859-868.

Patton, J.C., Avise, J.C., 1986. Evolutionary genetics of birds IV. Rates of protein divergence in waterfowl (Anatidae). Genetica 68, 129-143.

Peterson, R.T., Mountfort, G.A, Hollom, P.A.D., 1983. A Field Guide to the Birds of Britain and Europe, fourth ed. Wm Collins Sons, Glasgo.

Pitra, C., Lieckfeldt, D., Frahnert, S., Fickel, J., 2002. Phylogenetic relationships and ancestral areas of the bustards (Gruiformes: Otididae), inferred from mitochondrial DNA and nuclear intron sequences. Mol. Phylogenet. Evol. 23, 63-74.

Posada, D., Crandall, K.A., 1998. Modeltest: testing the model of DNA substitution. Bioinformatics 14, 817-818.

Prychitko, T.M., Moore, W.S., 1997. The utility of DNA sequences of an intron from the $B$ fibrinogen gene in phylogenetic analysis of woodpeckers (Aves: Picidae). Mol. Phylogenet. Evol. 8, 193-204.

Prychitko, T.M., Moore, W.S., 2000. Comparative evolution of the mitochondrial cytochrome $b$ gene and nuclear beta-fibrinogen intron 7 in woodpeckers. Mol. Biol. Evol. 17, 1101-1111.

Rhymer, J.M., Williams, M.J., Braun, M.J., 1994. Mitochondrial analysis of gene flow between New Zealand mallards (A. platyrhynchos) and grey ducks (A. superciliosa). Auk 111, 970-978.

Rhymer, J.M., Simberloff, D., 1996. Extinction by hybridization and introgression. Annu. Rev. Ecol. Syst. 27, 83-109.

Rohwer, F.C., Anderson, M.G., 1988. Female-biased philopatry, monogamy, and the timing of pair formation in migratory waterfowl. Curr. Ornithol. 5, 187-221.

Schneider, S., Keuffer, J.-M., Roessli, D., Excoffier, L., 2000. Arlequin, A Software Package for Population Genetics, version 2.000. University of Geneva.
Shapiro, L.H., Dumbacher, J.P., 2001. Adenylate kinase intron 5: a new nuclear locus for avian systematics. Auk 118, 248-255.

Shimodaira, H., Hasegawa, M., 1999. Multiple comparisons of log-likelihoods with applications to phylogenetic inference. Mol. Biol. Evol. 16, 1114-1116.

Sonobe, K., Usui, S., 1993. A Field Guide to the Waterbirds of Asia. Wild Bird Society of Japan, Tokyo.

Sorenson, M.D., Fleischer, R.C., 1996. Multiple independent transpositions of mitochondrial DNA control region sequences to the nucleus. Proc. Natl. Acad. Sci. USA 93, 15239-15243.

Sorenson, M.D., Ast, J.C., Dimcheff, D.E., Yuri, T., Mindell, D.P., 1999. Primers for a PCR-based approach to mitochondrial genome sequencing in birds and other vertebrates. Mol. Phylogenet. Evol. $12,105-114$.

Sorenson, M.D., Payne, R.B., 2001. A single ancient origin of brood parasitism in African finches: implications for host-parasite coevolution. Evolution 55, 2550-2567.

Sundstrom, H., Webster, M.T., Ellegren, H., 2003. Is the rate of insertion and deletion mutation male biased? Molecular evolutionary analysis of avian and primate sex chromosome sequences. Genetics 164, 259-268.

Swofford, D.L., 1999. PAUP*: Phylogenetic Analysis Using Parsimony (and other methods), version 4.0.

Talbot, S.L., Shields, G.F., 1996. Phylogeography of brown bears (Ursus arctos) of Alaska and paraphyly within the Ursidae. Mol. Phylogenet. Evol. 5, 477-494.

Tamura, K., Nei, M., 1993. Estimation of the number of nucleotide substitutions in the control region of mitochondrial dna in humans and chimpanzees. Mol. Biol. Evol. 10, 512-526.

Templeton, A.R., 1983. Phylogenetic inference from restriction endonuclease cleavage site maps with particular reference to the evolution of humans and the apes. Evolution 37, 221-244.

Tubaro, P.L., Lijtmaer, D.A., 2002. Hybridization patterns and the evolution of reproductive isolation in ducks. Biol. J. Linn. Soc. 77, 193 200.

Tuohy, J.M., McHugh, K.P., de Kloet, S.R., 1992. Systematic relationships among some Anatini as derived from restriction-endonuclease analysis of a repeated DNA component. Auk 109, 465-473.

Wilgenbusch, J., de Queiroz, K., 2000. Phylogenetic relationships among the phrynosomatid sand lizards inferred from mitochondrial DNA sequences generated by heterogeneous evolutionary processes. Syst. Biol. 49, 592-612.

Zink, R.M., Rohwer, S., Andreev, A.V., Dittmann, D.L., 1995. TransBeringia comparisons of mitochondrial DNA differentiation in birds. Condor 97, 639-649. 